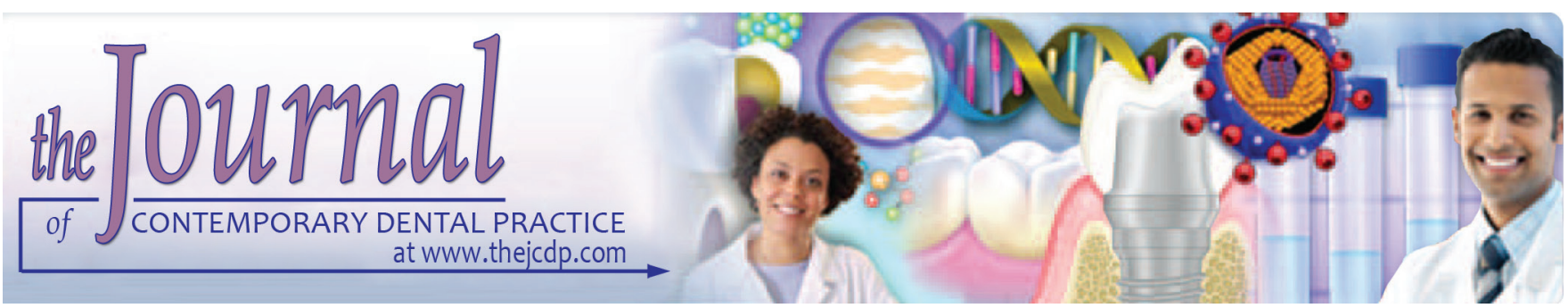

\title{
Assessment of the Effect of Simulated Rhinoplasty and Genioplasty on the Facial Profile Attractiveness of Patients with a Convex Face
}

${ }^{1}$ Saied Sadeghian, ${ }^{2}$ Amin Shirvani, ${ }^{3}$ Zeinab Azamian

\section{ABSTRACT}

Aim: This study was performed to evaluate the effect of rhinoplasty and genioplasty on facial profile attractiveness assessed by orthodontists and laypersons.

Materials and methods: In this study, posttreatment cephalograms of 30 class II patients with convex profile and nasal hump who had undergone camouflage treatment were traced. These profile outlines were modified by computer software to simulate rhinoplasty and genioplasty. Then, all these outlines were converted into silhouettes. There were four groups: no modification, rhinoplasty $(R)$, genioplasty $(G)$, and rhinoplasty plus genioplasty $(R G)$. Esthetic assessment of all patients was done by two panels: six orthodontists and six laypersons. Data were analyzed using Friedman's and Wilcoxon's test with a significance level of 0.05 .

Results: The highest mean esthetics scores belonged to RG $(3.9 \pm 0.6)$, followed by $R(3.5 \pm 0.5), G(2.4 \pm 0.5)$, and the initial image of the patients $(2.13 \pm 0.5)$. There was a significant improvement following all surgeries as determined by all evaluators $(p<0.001)$, except for orthodontists who did not find genioplasty more esthetic than no modification ( $p=0.139$ ). The mean score of esthetics by orthodontists was more than laypersons in all groups $(p>0.05)$.

Conclusion: Both rhinoplasty and genioplasty improved the attractiveness of the patients' facial profiles. The greatest improvement in the facial profile attractiveness in convex faces

\footnotetext{
${ }^{1}$ Department of Orthodontics, School of Dentistry, Torabinejad Dental Research Center, Isfahan University of Medical Sciences Isfahan, Islamic Republic of Iran

${ }^{2}$ Clear Advantage Orthodontics, Vancouver British Columbia Canada

${ }^{3}$ Department of Orthodontics, School of Dentistry, Kerman Oral and Dental Disease Center, Kerman University of Medical Sciences, Kerman, Islamic Republic of Iran

Corresponding Author: Zeinab Azamian, Department of Orthodontics, School of Dentistry, Kerman Oral and Dental Disease Center, Kerman University of Medical Sciences Kerman, Islamic Republic of Iran, Phone: +989134100546 e-mail: zeinab.azamian@gmail.com
}

was observed after simultaneous nasal hump elimination and chin argumentation procedures.

Clinical significance: Although both rhinoplasty and genioplasty could improve patients' profile, the best result is achieved when combination of them is used for treatment of convex facial profile patients.

Keywords: Convex profile, Facial attractiveness, Facial profile, Genioplasty, Rhinoplasty.

How to cite this article: Sadeghian S, Shirvani A, Azamian Z. Assessment of the Effect of Simulated Rhinoplasty and Genioplasty on the Facial Profile Attractiveness of Patients with a Convex Face. J Contemp Dent Pract 2018;19(6):719-725.

Source of support: Nil

Conflict of interest: None

\section{INTRODUCTION}

The primary goals of orthodontic treatment are to attain attractive appearance, better occlusal relationships, and maximum stability of these achievements. In recent years, orthodontic diagnosis and treatment planning have shifted attention from hard tissues to soft tissues, ${ }^{1}$ and the decision for treatment is ever-increasingly made to achieve a facial esthetic appearance rather than to correct dental and occlusal relationships. Demanding a facial esthetic appearance has been reported as the most common reason for patients' visits to orthodontic and maxillofacial surgery offices and centers. ${ }^{2,3}$

A fundamental fact about esthetics is that the five senses enjoy harmonious components. A face is considered to have an esthetic appearance that exhibits harmony between all its components and based on this fact, orthodontists and plastic surgeons evaluate the relationship between all the facial components. ${ }^{4}$ It has been stated that "The dorsal form of nose should be in harmony with other features of face." ${ }^{\prime 5}$ 
Class II patients comprise a significant percentage of orthodontic patients. Ast et $\mathrm{al}^{6}$ evaluated the occlusal relationships of 1,418 high school students aged 15 to 18 years and reported a prevalence rate of $23.8 \%$ for class II malocclusion. For these patients, decision-making between camouflage, orthodontic surgery and treatment with or without extraction is one of the major challenges in orthodontic treatment planning, considering the different and unpredictable effects they have on the facial profile and the patients' soft tissues after treatment. In patients with mild skeletal discrepancy, camouflage treatment is an accepted treatment modality. However, at the end of the treatment, the patient might have a convex profile.

The nasal profile is one of the most important determining variables in the treatment planning of class II patients. In a patient with a prominent nose, the camouflage treatment plan does not result in a very esthetic appearance. On the contrary, a nasal hump is usually seen in class II patients. The shape of the nose in skeletal class II malocclusion usually follows the overall convexity of the face. Growth pattern data from a growth and development study carried out by Bolton showed that the nasal hump in most cases develops in association with class II malocclusion. ${ }^{7}$ On the face, the nose and chin are considered important components of smile framework due to their position, and attention to their soft tissue profile might affect the attractiveness of the facial profile; therefore, they should be taken into account in orthodontic treatment planning. Patients who accept the camouflage treatment are sometimes encouraged to carry out adjunctive rhinoplasty and genioplasty procedures. In order to create ideal changes in facial appearance, making changes in both nose and chin might be needed. ${ }^{8}$

Currently, various techniques are available for the evaluation of facial attractiveness and perception of the facial profile: evaluation through observation of silhouettes, ${ }^{9-12}$ facial outline drawings, ${ }^{13,14}$ and photographs. ${ }^{15,16}$ The advantage of the use of silhouettes is the elimination of biases, such as gender, ethnicity, effect of cosmetics, hairstyle, and the form and color of the eyes. ${ }^{17}$ Davidenko ${ }^{18}$ reported that silhouettes provide sufficient data to estimate age and gender and even the attractiveness of the face.

Although the effect of esthetic surgeries on facial attractiveness has been evaluated in some cultures, ${ }^{11,12,19,20}$ no previous study was found in Iranian population. Hence, the aim of the present study was to evaluate the effect of rhinoplasty and genioplasty on the facial profile attractiveness of patients with a convex face.

\section{MATERIALS AND METHODS}

\section{Study Design}

The study protocol was approved by local university ethical committee. Orthodontic records of patients who
Table 1: Inclusion and exclusion criteria

\begin{tabular}{l}
\hline Inclusion criteria \\
\hline Angle skeletal class II malocclusion (ANB $=4-8)^{\star}$ \\
Age $>18$ years \\
Nasal hump \\
Camouflage treatment plan (nonsurgical) \\
Proper posttreatment cephalograms in maximum intercuspation \\
and with no lip strain ${ }^{* *}$ \\
Exclusion criteria \\
Previous dental or facial trauma \\
Congenital defects or syndromes \\
Rhinoplasty or orthognathic surgery
\end{tabular}

*Measurement of ANB angle was done precisely in all subjects using view box computer software; **Absence of lip strain was confirmed by assessment of posttreatment photographs at rest

were treated in the Department of Orthodontics, Faculty of Dentistry, Isfahan University of Medical Sciences, from April 2012 to April 2016 were assessed and documents of 30 patients were selected based on inclusion and exclusion criteria (Table 1). Only posttreatment cephalograms and the profile photographs at rest after treatment were used in this study.

\section{Preparation of Silhouettes}

Lateral cephalograms were scanned and digitized using Flatbed (HP Scanjet, Hewlett Packard, Böblingen, Germany) and a laptop (HP Pavilion Dv 6). Twenty-five soft tissue landmarks and 12 hard tissue landmarks (Fig. 1) were determined on a 15-inch color monitor with a resolution of $1366 \times 768$ pixels using View Box 4.0 (dHal Orthodontic Software, Athens, Greece) computer software program. At this stage, the angle between A-point, nasion, and B-point (ANB) was measured by the software program and two patients were excluded, as they had $\mathrm{ANB}>8$. Hence, 30 records were included in this study.

The initial digital tracing of the cephalograms of each patient was called image $\mathrm{A}$ and was considered as the reference image (Fig. 2A).

Prediction of genioplasty was carried out on the hard tissue. The bony advancement of the chin was carried out based on the S-line of the patient by a single maxillofacial surgeon. The amount of soft tissue advancement was determined by the values predicted by the software program. This image representing genioplasty was called image B (Fig. 2B).

Hump correction rhinoplasty was carried out on the nasal soft tissue by the same maxillofacial surgeon. The selected soft tissue landmarks intended for surgery were soft/above nasion, nasion, below nasion, bridge of nose, above pronasale, pronasale, and below pronasale. Surgery consisted of only the elimination of the nasal hump and creation of a mild concavity on the dorsum of 


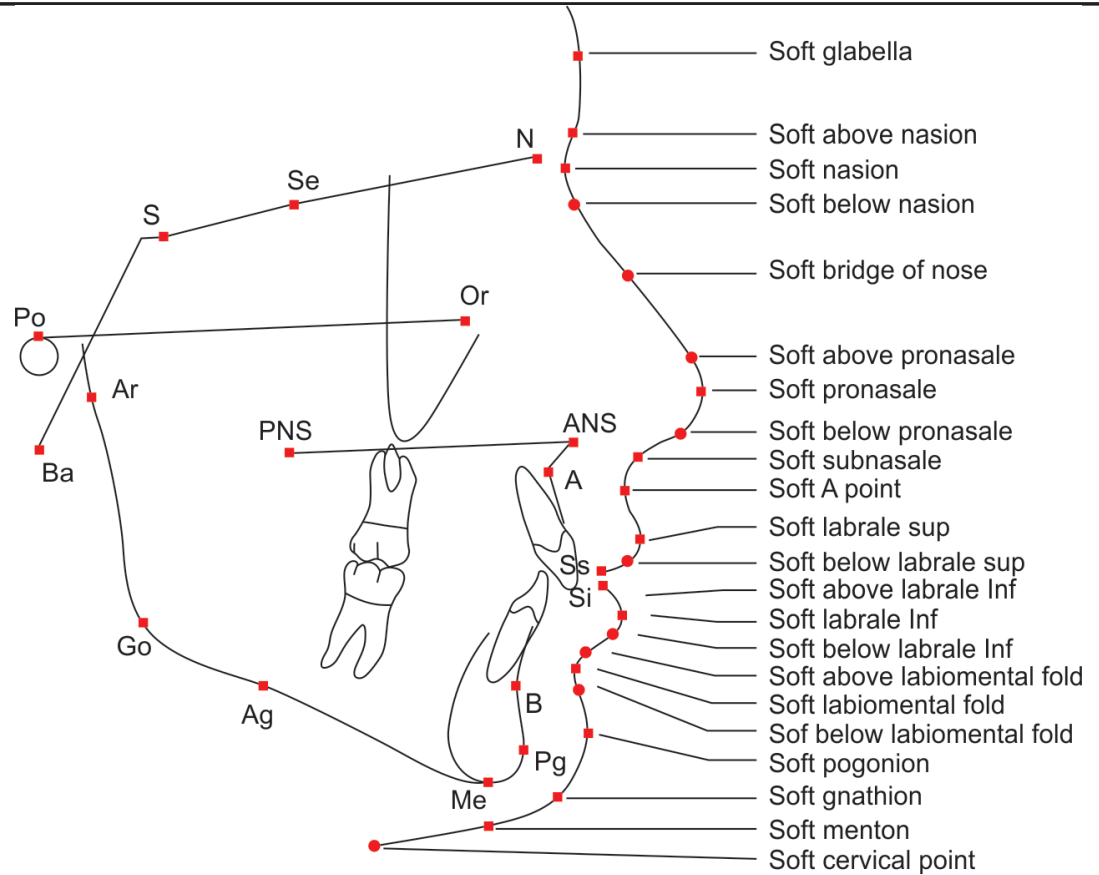

Fig. 1: Soft and hard tissue landmarks

the nose, without manipulating the patients' pronasale point. This image representing rhinoplasty was called image $\mathrm{C}$ (Fig. 2C).

In order to predict genioplasty and rhinoplasty, both previous surgeries were carried out using the same values in the transverse and vertical dimensions. This image representing rhinoplasty plus genioplasty was called image D (Fig. 2D).

Finally, each of the prepared images of the patients' facial profile outlines was converted into silhouettes using Photoshop (version 13.0, Adobe Systems, San Jose, CA) software program in order to eliminate the confounding factors (Figs 2E to $\mathrm{H}$ ).

\section{Assessment of Profile Preference}

A PowerPoint (Microsoft, Redmond, Washington, USA) presentation file was prepared including all the acquired images which consisted of 34 slides. Each slide consisted of four silhouette images of one patient. The silhouette images were set randomly. The code of each patient was mentioned at the top of each slide. The first four slides were duplicates of randomly selected slides and were not

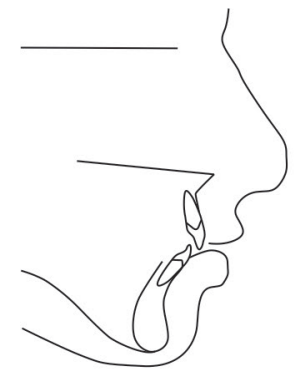

A

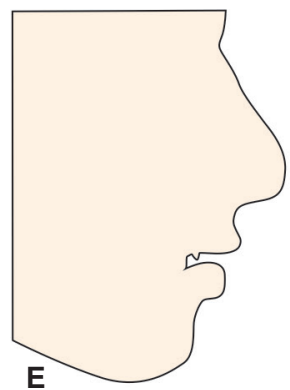

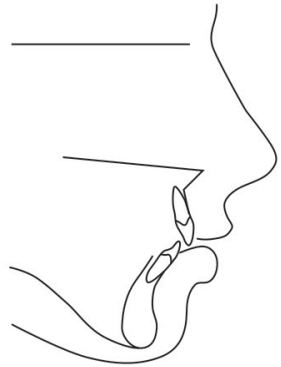

B

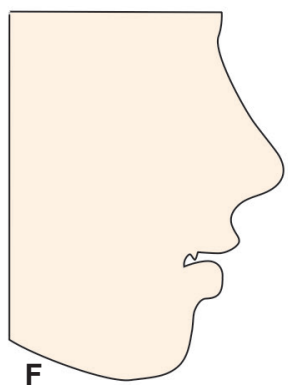

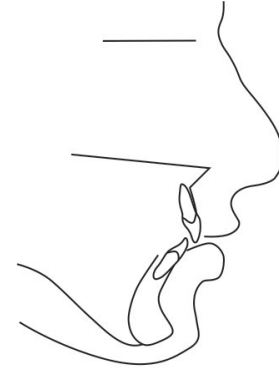

C

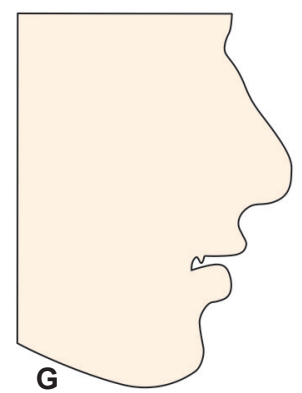

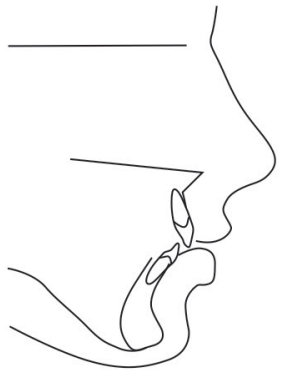

D

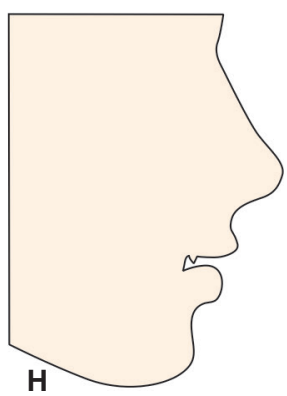

Figs 2A to H: Profile outlines (A) before surgery, (B) after rhinoplasty, (C) after genioplasty, (D) after rhinoplasty plus genioplasty, and $(E-H)$ corresponding silhouettes for subfigures $A$ to $D$ 
included in the statistical analysis. They were only used to prepare the minds and eyes of the observers and help them make a better judgment. The first slide was displayed for 60 seconds. The second slide was displayed for 48 seconds and the display time was decreased to 40 seconds (10 seconds for each image) for the rest the slides. The slides were displayed automatically, with no possibility to go back or stop it. There was a buzz at the end of the display of each slide and before the next slide was displayed.

The observers were placed in two panels: orthodontists and laypersons. The first panel included six orthodontists (three males and three females) who had been graduated from the same university. The laypersons consisted of six students (three males and three females) in fields other than art and dentistry. All observers lived in the same city. Each observer was given a questionnaire consisting 34 boxes. Each box contained four visual analog scale (VAS) scores and each VAS belonged to one image of each slide. The observers were instructed to rate the beauty of each image based on a 10-point VAS. In order to assess reliability of the test, two randomly selected observers repeated the process after 2 weeks under the same conditions and evaluation criteria.

\section{Statistical Analysis}

Data were evaluated using Statistical Package for the Social Sciences version 18 (SPSS, Chicago, USA). Friedman's test was used to evaluate differences in the mean esthetics scores of different surgical approaches. Wilcoxon's test was used to compare the mean esthetic scores between orthodontists and laypersons. Interclass correlation coefficient (ICC) test was done for interrater and intrarater reliability. All tests were done at a significance level of 0.05 .

\section{RESULTS}

Table 2 presents the mean esthetics scores of each profile based on the panel of observers. The highest mean esthetics scores among all observers belonged to rhinoplasty plus genioplasty image $(3.9 \pm 0.6)$, followed by rhinoplasty image $(3.5 \pm 0.5)$, genioplasty image $(2.4 \pm$ $0.5)$, and the initial image of the patients $(2.13 \pm 0.5)$ in descending order. There were significant differences in the mean esthetics scores between the orthodontists and the laypersons $(\mathrm{p}<0.05)$ (Table 2$)$. The mean score for each profile was not significantly different between male and female observers $(p>0.05)$.

When it is necessary to avoid type I error, a Bonferroni correction should be considered. ${ }^{21}$ Considering Bonferroni correction, Wilcoxon's test was used to perform pairwise comparisons between esthetics scores of four profiles (Table 3). The results, based on the opinions of all the observers, showed that following both rhinoplasty and rhinoplasty plus genioplasty, the mean esthetics scores of the patient's profile improved significantly compared with the patients' initial profiles $(p<0.001)$. Based on the opinions of laypersons, there was a significant change in the mean score of the patients' profile after genioplasty $(p<0.001)$; however, based on the opinions of orthodontists, the difference was not significant ( $p=0.139)$.

Based on the opinions of all the observers, there was a greater increase in the mean esthetics scores after the two adjunctive surgeries compared with the situation when only one of the surgeries was carried out $(p<0.001)$.

The results of ICC for interrater reliability were 0.6 for initial tracing $(p<0.001), 0.71$ for rhinoplasty $(p<0.001)$, 0.7 for genioplasty $(p<0.001)$, and 0.61 for rhinoplasty plus genioplasty $(\mathrm{p}<0.001)$. The ICC intrarater reliability was 0.6 for orthodontist and 0.843 for layperson $(p<0.001)$. Based on these results, the process had a good inter- and intrarater agreement.

\section{DISCUSSION}

A study on an Iranian population showed that this population bears the highest resemblance to the Caucasians.

Table 2: Mean esthetic scores of patient profiles for each panel

\begin{tabular}{|c|c|c|c|c|c|c|c|c|}
\hline \multirow[b]{2}{*}{ Panels } & \multicolumn{2}{|c|}{ Initial } & \multicolumn{2}{|c|}{ Rhinoplasty } & \multicolumn{2}{|c|}{ Genioplasty } & \multicolumn{2}{|c|}{ Rhinoplasty + Genioplasty } \\
\hline & Mean & $S D$ & Mean & $S D$ & Mean & $S D$ & Mean & $S D$ \\
\hline Orthodontists & 2.55 & 0.66 & 3.68 & 0.5 & 2.71 & 0.66 & 4.03 & 0.68 \\
\hline Laypersons & 1.72 & 0.5 & 3.44 & 0.57 & 2.13 & 0.48 & 3.81 & 0.61 \\
\hline$p$-value ${ }^{*}$ & $<0.001$ & & 0.006 & & $<0.001$ & & 0.033 & \\
\hline
\end{tabular}

SD: Standard deviation; *Wilcoxon test

Table 3: Significance of multiple comparisons of esthetic scores

\begin{tabular}{|c|c|c|c|c|c|c|}
\hline & \multicolumn{2}{|c|}{ Rhinoplasty } & \multicolumn{2}{|c|}{ Genioplasty } & \multicolumn{2}{|c|}{ Rhinoplasty + Genioplasty } \\
\hline & Orthodontist & Laypersons & Orthodontist & Laypersons & Orthodontist & Laypersons \\
\hline Initial & $<0.001^{*}$ & $<0.001^{*}$ & 0.139 & $<0.001^{*}$ & $<0.001^{*}$ & $<0.001^{*}$ \\
\hline Rhinoplasty & - & - & $<0.001^{*}$ & $<0.001^{*}$ & $0.001^{*}$ & $<0.001^{*}$ \\
\hline Genioplasty & - & - & - & - & $<0.001^{*}$ & $<0.001^{*}$ \\
\hline
\end{tabular}

*Significant using Wilcoxon test 
Attractive Iranians have a straight facial profile, a small ascending nose, a slightly protruding maxilla and prominent lips. ${ }^{22}$ It is of great importance to determine the effect of surgical interventions on esthetics and to consider the amount of this effect during treatment planning. In the present study, the effect of rhinoplasty and genioplasty separately and simultaneously on the attractiveness of the facial profile was evaluated. The results showed that based on the opinions of orthodontists and laypersons, the different surgical approaches significantly affected the facial profile esthetics.

The patients' facial profile attractiveness improved after hump correction rhinoplasty. The results of another study in an Iranian population showed that a prominent nose is not considered beautiful; furthermore, it causes the lips to appear retruded. ${ }^{22}$ Other studies, consistent with the present study, have shown that a less prominent nose with a higher nasal tip and a more obtuse nasolabial fold is more acceptable in many cultures, including Brazil, ${ }^{23}$ Yemen, Saudi Arabia, ${ }^{24}$ United Kingdom, ${ }^{12}$ and China. ${ }^{19}$ Also, it has been stated that in patients with class II normal profile, a straight nasal dorsum is more attractive than a convex dorsum and these patients would benefit from surgical correction of a convex dorsum. ${ }^{9}$ In this survey on an Iranian population with a convex face, the result showed that a straight nose is more attractive compared with a nose with a convex profile (hump).

The most common adjunctive esthetic surgical procedure in dentofacial patients is genioplasty. ${ }^{7}$ Based on the results of the present study, according to the opinions of orthodontists, the patients' facial profile esthetics improved dafter genioplasty compared with that before treatment; however, such an increase in esthetic appearance was not statistically significant. However, based on the opinion of laypersons, genioplasty significantly increased the facial profile esthetics of the patients. These findings are consistent with those of a study in India which showed that people are interested in straight profiles with prominent chins, and profiles with SNB angles of $\geq 78^{\circ}$ resulted in more prominent chins and more attractive profiles. ${ }^{25}$ In addition, in a Turkish, ${ }^{26}$ Italian, ${ }^{27}$ Brazilian, ${ }^{28}$ and $\mathrm{Arab}^{11}$ populations too, more prominent chins in the facial profiles of males were considered more attractive.

The results of the present study showed that based on the opinions of all the observers, the facial profile esthetics improved after simultaneous rhinoplasty and genioplasty. In addition, the most esthetic facial profiles, based on the opinions of all observers, were achieved after simultaneous rhinoplasty and genioplasty, followed by rhinoplasty alone and genioplasty alone. Studies carried out on whites, African Americans, and Yemenese populations have shown that both specialists and laypersons prefer straight profiles. ${ }^{19,29}$ In addition, in the Asian populations, too, the orthodontists had a more positive opinion about more straight facial profiles. ${ }^{30,31}$

The preference of simultaneous rhinoplasty and genioplasty did not hold true for all the facial profiles and there was individual variability. These data confirm the fact that the attractiveness of the facial profile is not solely under the influence of the nose and chin forms. Other facial components could also exert different effects on esthetics. Hence, rhinoplasty, elimination of the nasal hump, genioplasty, and chin augmentation cannot be considered prerequisites for all the patients as a solution to improve attractiveness.

In the present study, orthodontists gave mean higher esthetics scores to the subjects compared with the laypersons, consistent with the results of similar studies. ${ }^{32-36}$ It has been reported that mass media and the educations received by orthodontists have affected their sense of beauty. ${ }^{32}$ On the contrary, orthodontists have attained more logical and achievable criteria considering their experience in relation to the promotion of esthetics; the opposite consideration is the general population's ideal mental picture which has been affected by Hollywood stars. However, some other evaluations have shown that laypersons are interested, more than orthodontists and surgeons, in rating the faces normal or more beautiful. ${ }^{37}$ It seems that the viewpoint of laypersons is more important and should be considered during treatment planning.

Generally, there was no difference in the preferred facial profile between the observers of the two panels. The most esthetic facial profile in both groups was achieved after simultaneous rhinoplasty and genioplasty, indicating that the final result in relation to esthetics is not very related to the background of individuals; technical educations do not finally change the background; and finally, the esthetics goals of orthodontists in relation to the nose and chin are consistent with the esthetic viewpoint of the community's ordinary members. The results of the present study are consistent with those of other studies in other communities ${ }^{9,20}$ and even in the Iranian population. $^{38}$

Evaluation of facial esthetics is a subjective and complex issue. It is difficult to determine objective criteria for the evaluation of facial attractiveness. Several factors, such as the effect of cultural differences and the community make it difficult to make objective judgments and create criteria for the evaluation of esthetics. ${ }^{39}$ In the present study, the observers were selected from one city to minimize culture-related variations. Use of numeric scores and quantification of criteria in the field of facial esthetics and attractiveness, increases the sensitivity of judgments made compared with the qualitative description of esthetics. However, such quantification might lead 
to biases among the observers. ${ }^{40,41}$ Of all the techniques used for the quantification of emotions, VAS is more acceptable for observers since it eliminates the bias resulting from scoring in numeric scale and equal appearing interval scale. ${ }^{41}$ The VAS has so far been used for the evaluation of opinions about the different aspects of dentofacial appearance: the esthetics of the facial profile, dental esthetics, smile esthetics, etc. This technique is easy, simple, and fast. However, this does not mean that it does not have its specific weaknesses and limitations. ${ }^{42}$ Observers tend to spread their responses over the entire scale and avoid the ends at the anchor points, independently of the actual preferences. ${ }^{41,42}$ The limitations of the use of VAS are not greater than those of description with the use of words. However, when words are used for descriptions (such as very attractive, attractive, moderate, and not attractive) there is no certainty that the interval between two descriptive words is the same in the mind of an observer. In addition, use of similar words by different observers might not mean a similarity of their opinions. Therefore, visual analogs seem to be more effective compared with verbal analogs. ${ }^{40}$

Similar to the recently published studies, ${ }^{11,12,43-45}$ in the present study, an attempt was made to eliminate confounding factors with the use of silhouettes for evaluations. However, it has been suggested that silhouettes might affect the evaluations, and the accuracy of assessment of esthetics could be increased if silhouettes in combination with other evaluation techniques are applied. ${ }^{10,20,46}$

Finally, it is of great importance to predict the final outcome of orthodontic treatments, especially when growth modification or surgical interventions are involved. ${ }^{47,48}$ Based on the results, convex profiles could be significantly improved by combination of rhinoplasty and genioplasty.

\section{CONCLUSION}

Considering the subjective nature of the evaluation of esthetics and the confounding factors in this respect, the following conclusions could be made based on the results of the present study on an Iranian population:

- The opinions of the orthodontists and laypersons about the preferred facial profile were the same.

- Both rhinoplasty and genioplasty improve the attractiveness of the patients' facial profiles.

- Nasal hump elimination surgery in convex faces results in greater improvement in the patients' profile compared with chin argumentation procedure.

- In the Iranian subjects with a convex face, a straight nose is more attractive compared with a nose with a convex profile (hump).
- The greatest improvement in the facial profile attractiveness in convex faces was observed after simultaneous nasal hump elimination and chin argumentation procedures.

\section{CLINICAL SIGNIFICANCE}

In order to achieve the most desirable esthetic results for orthodontic patients, genioplasty and rhinoplasty could be indicated. Although both of these surgeries could improve patients' profile, the best result is achieved when a combination of them is used for convex facial profile patients.

\section{REFERENCES}

1. Sarver DM, Ackerman JL. Orthodontics about face: the reemergence of the esthetic paradigm. Am J Orthod Dentofacial Orthop 2000 May;117(5):575-576.

2. Lecocq G, Truong Tan Trung L. Smile esthetics: calculated beauty? Int Orthod 2014;12:149-170.

3. Behnia H, Esmaeelinejad M, Eslamian L, Motamedian SR. New technique for midpalatal osteotomy in surgicallyassisted rapid palatal expansion. Br J Oral Maxillofac Surg 2017;55:556-557.

4. Jacobson, A.; White, L. Radiographic cephalometry: from basics to 3-D imaging. St. Louis (MO): Mosby; 2007. p. 141.

5. Gulsen A, Okay C, Aslan BI, Uner O, Yavuzer R. The relationship between craniofacial structures and the nose in Anatolian Turkish adults: a cephalometric evaluation. Am J Orthod Dentofacial Orthop 2006 Aug;130(2):131.e15-131.e25.

6. Ast DB, Carlos JP, Cons NC. The prevalence and characteristics of malocclusion among senior high school students in upstate New York. Am J Orthod 1965 Jun;51:437-445.

7. Proffit, WR.; White, RP.; Sarver, DM. Evaluation of soft tissues. In: Contemporary treatment of dentofacial deformity. Evaluation of facial soft tissues. St. Louis (MO): Mosby; 2003. p. 97.

8. Proffit, WR.; Fields, HW.; Sarver, DM.; Ackerman, JL. Combined surgery and orthodontic treatment. In: Proffit WR, Fields HW, editors. Contemporary orthodontics. Canada: Mosby; 2012. p. 705.

9. Morad G, Behnia H, Motamedian SR, Shahab S, Gholamin P, Khosraviani K, Nowzari H, Khojasteh A. Thickness of labial alveolar bone overlying healthy maxillary and mandibular anterior teeth. J Craniofac Surg 2014 Nov;25(6):1985-1991.

10. Behnia H, Motamedian SR, Kiani MT, Morad G, Khojasteh A. Accuracy and reliability of cone beam computed tomographic measurements of the bone labial and palatal to the maxillary anterior teeth. Int J Oral Maxillofac Implants. 2015 Nov-Dec;30(6):1249-1255.

11. Al Taki A, Guidoum A. Facial profile preferences, self-awareness and perception among groups of people in the United Arab Emirates. J Orthod Sci 2014 Apr;3(2):55-61.

12. Naini FB, Cobourne MT, Garagiola U, McDonald F, Wertheim D. Nasofacial angle and nasal prominence: a quantitative investigation of idealized and normative values. J Craniomaxillofac Surg 2016 Apr;44(4):446-452.

13. Prahl-Andersen B, Boersma H, van der Linden FP, Moore AW. Perceptions of dentofacial morphology by laypersons, general dentists, and orthodontists. J Am Dent Assoc 1979 Feb;98(2):209-212. 
14. Kiyak HA, Zeitler DL. Self-assessment of profile and body image among orthognathic surgery patients before and two years after surgery. J Oral Maxillofac Surg 1988 May;46(5):365-371.

15. Kerr WJ, O'Donnell JM. Panel perception of facial attractiveness. Br J Orthod 1990 Nov;17(4):299-304.

16. Mejia-Maidl M, Evans CA, Viana G, Anderson NK, Giddon DB. Preferences for facial profiles between Mexican Americans and Caucasians. Angle Orthod 2005 Nov;75(6):953-958.

17. Shelly AD, Southard TE, Southard KA, Casko JS, Jakobsen JR, Fridrich KL, Mergen JL. Evaluation of profile esthetic change with mandibular advancement surgery. Am J Orthod Dentofacial Orthop 2000 Jun;117(6):630-637.

18. Davidenko N. Silhouetted face profiles: a new methodology for face perception research. J Vis 2007 Mar;7(4):6.

19. Lew KK, Ho KK, Keng SB, Ho KH. Soft-tissue cephalometric norms in Chinese adults with esthetic facial profiles. J Oral Maxillofac Surg 1992 Nov;50(11):1184-1189; discussion 1189-1190.

20. Coleman GG, Lindauer SJ, Tufekci E, Shroff B, Best AM. Influence of chin prominence on esthetic lip profile preferences. Am J Orthod Dentofacial Orthop 2007 Jul;132(1): 36-42.

21. Armstrong RA. When to use the Bonferroni correction. Ophthalmic Physiol Opt 2014 Sep;34(5):502-508.

22. Khosravanifard B, Rakhshan V, Raeesi E. Factors influencing attractiveness of soft tissue profile. Oral Surg Oral Med Oral Pathol Oral Radiol 2013 Jan;115(1):29-37.

23. Scavone H Jr, Trevisan H Jr, Garib DG, Ferreira FV. Facial profile evaluation in Japanese-Brazilian adults with normal occlusions and well-balanced faces. Am J Orthod Dentofacial Orthop 2006 Jun;129(6):721.e1-721.e5.

24. Al-Gunaid T, Yamada K, Yamaki M, Saito I. Soft-tissue cephalometric norms in Yemeni men. Am J Orthod Dentofacial Orthop 2007 Nov;132(5):576.e7-576.e14.

25. Gautam G, Shashikalakumari V, Garg G. Facial attractiveness influenced by lower face vertical proportions and mandibular prominence. Orthodontic Waves 2013 Mar;72(1):30-35.

26. Turkkahraman $H$, Gokalp H. Facial profile preferences among various layers of Turkish population. Angle Orthod 2004 Oct;74(5):640-647.

27. Sforza C, Laino A, D'Alessio R, Grandi G, Tartaglia GM, Ferrario VF. Soft-tissue facial characteristics of attractive and normal adolescent boys and girls. Angle Orthod 2008 Sep;78(5):799-807.

28. Oliveira MD, Silveira BL, Mattos CT, Marquezan M. Facial profile esthetic preferences: perception in two Brazilian states. Dental Press J Orthod 2015 May-Jun;20(3):88-95.

29. Hall D, Taylor RW, Jacobson A, Sadowsky PL, Bartolucci A. The perception of optimal profile in African Americans versus white Americans as assessed by orthodontists and the lay public. Am J Orthod Dentofacial Orthop 2000 Nov;118(5):514-525.

30. Alcalde RE, Jinno T, Orsini MG, Sasaki A, Sugiyama RM, Matsumura T. Soft tissue cephalometric norms in Japanese adults. Am J Orthod Dentofacial Orthop 2000 Jul;118(1): 84-89.

31. Mantzikos T. Esthetic soft tissue profile preferences among the Japanese population. Am J Orthod Dentofacial Orthop 1998 Jul;114(1):1-7.
32. Sutter RE Jr, Turley PK. Soft tissue evaluation of contemporary Caucasian and African American female facial profiles. Angle Orthod 1998 Dec;68(6):487-496.

33. Spyropoulos MN, Halazonetis DJ. Significance of the soft tissue profile on facial esthetics. Am J Orthod Dentofacial Orthop 2001 May;119(5):464-471.

34. Roden-Johnson D, Gallerano R, English J. The effects of buccal corridor spaces and arch form on smile esthetics. Am J Orthod Dentofacial Orthop 2005 Mar;127(3):343-350.

35. McNamara L, McNamara JA Jr, Ackerman MB, Baccetti T. Hard- and soft-tissue contributions to the esthetics of the posed smile in growing patients seeking orthodontic treatment. Am J Orthod Dentofacial Orthop 2008 Apr;133(4):491-499.

36. Zulfiqar K, Bahir U, Durrani OK, Kiani H. Assessment of the most preferred facial profile amongst patients and Orthodontists. Pakistan Orthodont J 2013 Dec;5(2):38-43.

37. Melo AR, Conti A, Almeida-Pedrin RR, Didier V, Valarelli DP, Capelozza Filho L. Evaluation of facial attractiveness in black people according to the subjective facial analysis criteria. Dental Press J Orthod 2017;22:75-81.

38. Oshagh M, Aleyasin ZS, Roeinpeikar M. The effects of forehead and neck positions on profile esthetics. Eur J Esthet Dent 2012 Winter;7(4):454-466.

39. Tole N, Lajnert V, Kovacevic Pavicic D, Spalj S. Gender, age, and psychosocial context of the perception of facial esthetics. J Esthet Restor Dent 2014 Mar-Apr;26(2):119-130.

40. Appukuttan D, Vinayagavel M, Tadepalli A. Utility and validity of a single-item visual analog scale for measuring dental anxiety in clinical practice. J Oral Sci 2014;56:151-156.

41. Sundareswaran S, Ramakrishnan R. The Facial Aesthetic index: An additional tool for assessing treatment need. J Orthod Sci 2016;5:57-63.

42. Schabel BJ, McNamara JA Jr, Franchi L, Baccetti T. Q-sort assessment vs visual analog scale in the evaluation of smile esthetics. Am J Orthod Dentofacial Orthop 2009 Apr;135 (4 Suppl):S61-S71.

43. Mergen JL, Southard KA, Dawson DV, Fogle LL, Casko JS, Southard TE. Treatment outcomes of growing Class II Division 1 patients with varying degrees of anteroposterior and vertical dysplasias, Part 2. Profile silhouette evaluation. Am J Orthod Dentofacial Orthop 2004 Apr;125(4):457-462.

44. Sloss EA, Southard KA, Qian F, Stock SE, Mann KR, Meyer DL, Southard TE. Comparison of soft-tissue profiles after treatment with headgear or Herbst appliance. Am J Orthod Dentofacial Orthop 2008 Apr;133(4):509-514.

45. Mann KR, Marshall SD, Qian F, Southard KA, Southard TE. Effect of maxillary anteroposterior position on profile esthetics in headgear-treated patients. Am J Orthod Dentofacial Orthop 2011 Feb;139(2):228-234.

46. Hockley A, Weinstein M, Borislow AJ, Braitman LE. Photos vs silhouettes for evaluation of African American profile esthetics. Am J Orthod Dentofacial Orthop 2012 Feb;141(2): 161-168.

47. Tehranchi A, Saedi S, Motamedian SR, Rohani K. Radiographic evaluation of frontal sinus dimensions and anatomic variations. Br J Med Med Res 2015 May;8(5):454-462.

48. Tehranchi A, Motamedian SR, Saedi S, Kabiri S, Shidfar S. Correlation between frontal sinus dimensions and cephalometric indices: a cross-sectional study. Eur J Dent 2017 Jan-Mar;11(1):64-70. 